\title{
Correction to: Using the Theory of Planned Behavior to Predict Korean College Students' Help-Seeking Intention
}

\author{
Ji-Yeon Lee, Dr, PhD \\ Yun-Jeong Shin, PhD
}

\author{
Correction to: J Behav Health Serv Res. \\ https://doi.org/10.1007/s11414-020-09735-z
}

Please note the below funding statements, which were missing in the published article.

Dr. Ji-yeon Lee's work was supported by Hankuk University of Foreign Studies Research Fund.

This work was supported by the Ministry of Education of the Republic of Korea and the National Research Foundation of Korea (NRF-2017S1A5A8019931).

Publisher's Note Springer Nature remains neutral with regard to jurisdictional claims in published maps and institutional affiliations. 